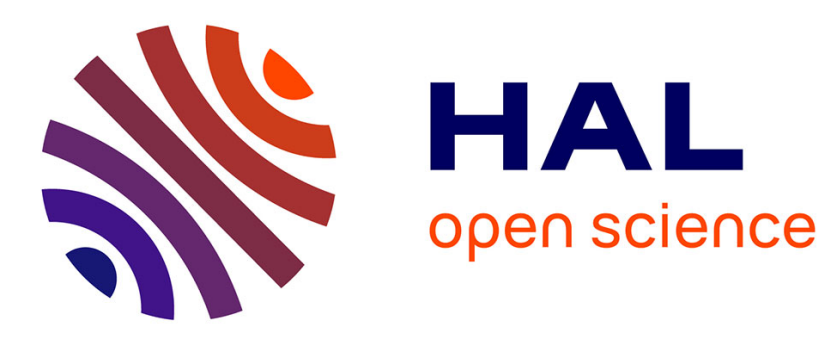

\title{
Damping Evolution During Precipitation in Al-Mg-Si Alloys
}

C. Xie, R. Schaller, W. Benoit, C. Jaquerod

\section{To cite this version:}

C. Xie, R. Schaller, W. Benoit, C. Jaquerod. Damping Evolution During Precipitation in Al-Mg-Si Alloys. Journal de Physique IV Proceedings, 1996, 06 (C8), pp.C8-301-C8-304. 10.1051/jp4:1996865 . jpa-00254673

\section{HAL Id: jpa-00254673 https://hal.science/jpa-00254673}

Submitted on 1 Jan 1996

HAL is a multi-disciplinary open access archive for the deposit and dissemination of scientific research documents, whether they are published or not. The documents may come from teaching and research institutions in France or abroad, or from public or private research centers.
L'archive ouverte pluridisciplinaire HAL, est destinée au dépôt et à la diffusion de documents scientifiques de niveau recherche, publiés ou non, émanant des établissements d'enseignement et de recherche français ou étrangers, des laboratoires publics ou privés. 
JOURNAL DE PHYSIQUE IV

Colloque C8, supplément au Journal de Physique III, Volume 6, décembre 1996

\title{
Damping Evolution During Precipitation in Al-Mg-Si Alloys
}

\author{
C.Y. Xie, R. Schaller, W. Benoit and C. Jaquerod* \\ Ecole Polytechnique Fédérale de Lausanne, Institut de Génie Atomique, 1015 Lausanne, Switzerland \\ * Alusuisse Swiss Aluminium Ltd., Sierre, 3965 Chippis, Switzerland
}

\begin{abstract}
Damping capacity and shear elastic modulus measurements have been carried out during precipitation in AlMgSi alloys. After the specimen has been aged at the temperature corresponding to the lowest thermoelectric power, both damping and elastic modulus increase comparing with the as-quenched state. The effect of strain amplitude was investigated in specimens aged at different temperatures. A critical strain amplitude, $\varepsilon_{\mathrm{c}}$, has been observed. For strain amplitudes higher than $\varepsilon_{\mathfrak{c}}$, the damping capacity increases strongly with strain amplitude. In addition a relaxation peak appears around $420 \mathrm{~K}$ after ageing. The strong damping-amplitude effect and the relaxation peak are attributed to the breakaway of the dislocation from the solute atoms at low temperature and to the dragging of these solute atoms by the dislocations at high temperature respectively.
\end{abstract}

\section{INTRODUCTION}

It is an important challenge to design structural materials that reduce mechanical vibrations. These are responsible for many undesirable effects which occur in dynamical engineering systems: the premature fatigue of components, the performance reduction of machines and the noise pollution. In order to control these harmful effects, high damping capacity alloys are considered to be good candidate materials since they can internally dissipate mechanical energy and thereby ensure a lower vibration amplitude. Several review papers [1-5] have been devoted to this subject during the past twenty years. It appears that most of the frequently used metals and alloys exhibit a low damping capacity, and hence are limited in their applications and performance in dynamic structures. Accordingly, researchers have sought to develop high damping metals through the use of innovative materials-processing techniques. To solve the problems caused by mechanical vibrations in the machine-tool industry, in robotics or in transport systems, the development of high damping aluminum alloys is proposed.

In general, aluminum alloys present a low density and a good stiffness, but a low damping capacity. In order to increase the damping level without losing the mechanical strength, a very important thing is to favor damping mechanisms which are independent of the strengthening mechanisms. As strengthening in aluminum alloys is mainly due to precipitation hardening, the idea is to favor damping mechanisms in the solid solution which surrounds the precipitates. For instance, dislocation loops, which are firmly pinned at their ends by precipitates, could vibrate between the pinning points provided that the solute concentration in the matrix would be low. To follow the solute concentration evolution during precipitation, thermoelectric power (TEP) has systematically been measured during annealing since it is very sensitive to the concentration of solute atoms in the matrix. Our goal is then to study the damping spectra corresponding to different precipitation stages or to different TEP levels.

\section{EXPERIMENTAL PROCEDURES}

AlMgSi alloys (6082) were prepared by Alusuisse Ltd, Sierre, Switzerland. Plate specimens of a cross section of $4 \times 1 \mathrm{~mm}$ were obtained by machining. The effective length for both free-free bar measurements and inverted torsional pendulum was $40 \mathrm{~mm}$. The free-decay method was used for the damping measurements and the modulus evolution was obtained from the resonant frequency. TEP measurements were performed on specimens with dimensions of $1 \times 4 \times 100 \mathrm{~mm}$. After being solution treated at $813 \mathrm{~K}$ for $1 \mathrm{~h}$, the specimens were quenched into cold water and subjected to isothermal cumulative annealing. The 
chosen annealing temperatures were: $323,373,423,478,523$ and 573K. The TEP apparatus is equipped with pure aluminum blocks. The low temperature block, $T$, and the difference between the low and high temperature blocks, $\Delta \mathrm{T}$, were 291 and $10 \mathrm{~K}$, respectively. The temperature of the measurement, $\mathrm{T}_{\mathrm{m}}$, has been considered to be $T_{m}=T+\Delta T / 2=296 K$.

\section{RESULTS}

Figure 1 shows the TEP evolution as a function of the annealing time at different annealing temperatures for the specimen after a solution-treatment at $813 \mathrm{~K}$ for $1 \mathrm{~h}$ followed by quenching into cold water. Curves 1-6 correspond to the different annealing temperatures. The TEP values, which have been normalized with respect to the as-quenched value, decrease when the annealing time increases. The results show that the TEP presents the lowest level when the alloys has been aged at $478 \mathrm{~K}$ for $3 \mathrm{hs}$, which means that the concentration of $\mathrm{Si}$ and $\mathrm{Mg}$ in matrix in this situation is the lowest [6]. This case will favor the dislocation mobility, and therefore can be used to increase dislocation damping in the specimens.

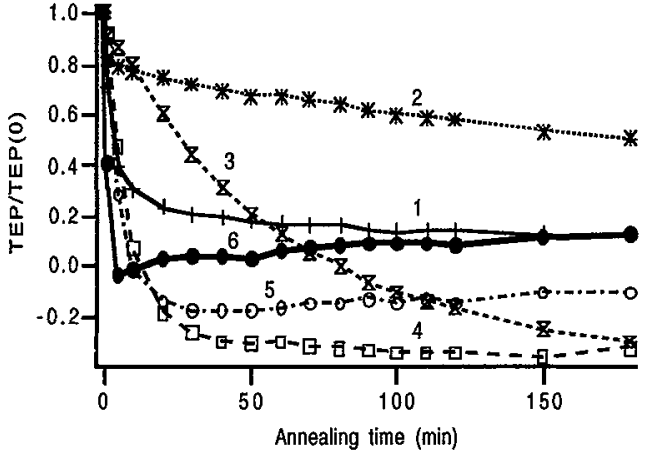

Figure 1: Normalized TEP as a function of the annealing time at different temperatures after solution-treated at $813 \mathrm{~K} / 1 \mathrm{~h}$. Curves $1-6$ correspond to the annealing temperatures of $323,373,423,478,523$ and $573 \mathrm{~K}$, respectively.

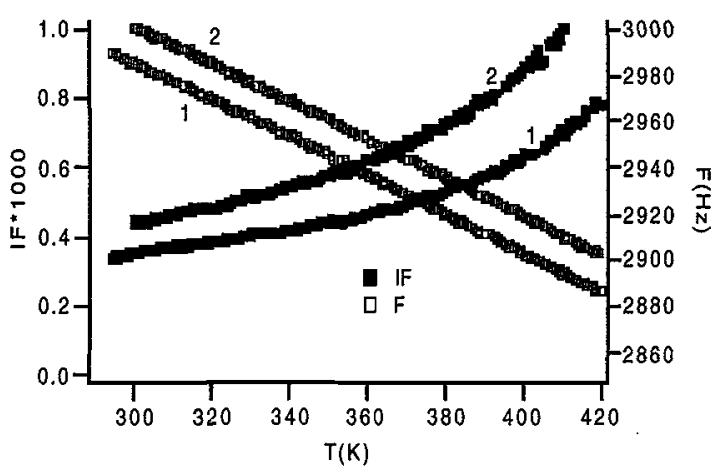

Figure 2: Acoustic damping capacity and Young's modulus (resonant frequency) as a function of temperature in a specimen after quenching (curves 1 ) and after ageing at $478 \mathrm{~K} / 3 \mathrm{~h}$ (curves 2 ).

Figure 2 shows the internal friction and the frequency (elastic modulus) curves measured in a free-free bar apparatus in the aluminum alloy after quenching (curves 1) and after ageing at the temperature of $478 \mathrm{~K}$ where the TEP is minimum (curves 2). Both the damping capacity and the elastic modulus are higher in the aged specimen with respect to the as-quenched state in the entire temperature range investigated. Although this increment is not very high, it promises that AlMgSi alloy may be developed into a new kind of high damping alloys.

The low frequency $(\sim 1 \mathrm{~Hz})$ internal friction spectrum measured in a torsion pendulum during cooling after ageing at $523 \mathrm{~K} / 10 \mathrm{~h}$ is shown in Fig.3. This spectrum is mainly composed of a damping peak at about 420 $\mathrm{K}$. The effect of strain amplitude on this spectrum is evident through the curves 1 to 5 which correspond to strain amplitudes of $4 \times 10^{-4}, 7 \times 10^{-4}, 1 \times 10^{-3}, 2 \times 10^{-3}$ and $3 \times 10^{-3}$, respectively. When the amplitude is lower than $1 \times 10^{-3}$, the amplitude dependence of damping is weak. However, when the strain amplitudes is higher than $1 \times 10^{-3}$, a strong strain amplitude effect is observed, which means that the damping increases drastically with increasing amplitude at a constant temperature. This leads to a high damping $(\sim 0.01)$ at room temperature. Therefore, $1 \times 10^{-3}$ can be considered a critical strain amplitude for AlMgSi alloy.

The damping peak is thermally activated. Fig.4 gives the Arrhenius plot corresponding to the peak. The activation energy is $1.54 \mathrm{eV}$ and the pre-exponential factor $-10^{-18} \mathrm{sec}$. 


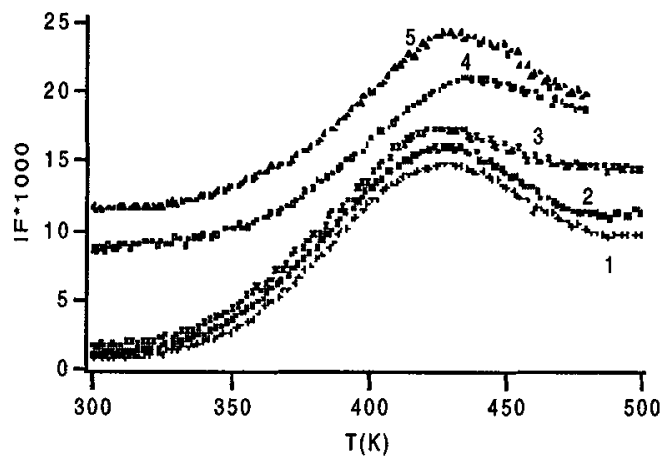

Figure 3: Damping spectra measured in a torsion pendulum after ageing at $523 \mathrm{~K} / 10 \mathrm{~h}$. Curves $1-5$ correspond to strain amplitudes of $4 \times 10^{-4}, 7 \times 10^{-4}, 1 \times 10^{-3}, 2 \times 10^{-3}$ and $3 \times 10^{-3}$.

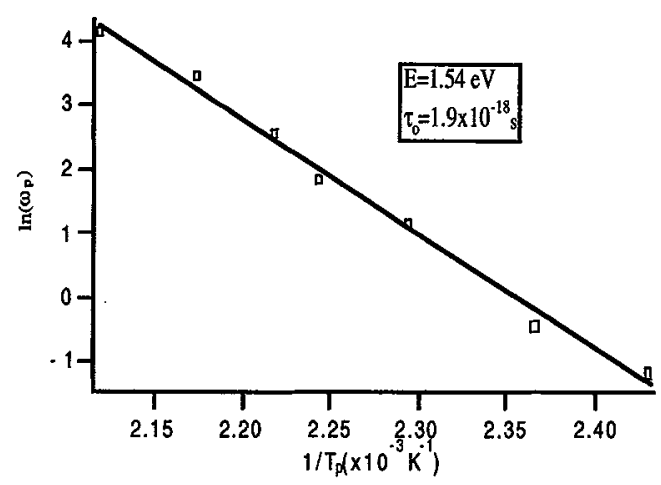

Figure 4: The Arrhenius plot of the peak measured at a strain amplitude of $2 \times 10^{-5}$.

$\omega=2 \pi f$ : angular frequency; $T_{\mathrm{p}}$ : the peak temperature.

\section{DISCUSSION}

The low frequency $(1 \mathrm{~Hz})$ internal friction spectrum of Al-Mg-Si alloy is mainly composed of a relaxation peak around $420 \mathrm{~K}$ which is superimposed to an exponential increase of the background with the temperature [7]. This peak appears after precipitation and is certainly associated with the appearance of the semicoherent $\boldsymbol{\beta}^{\prime}$ precipitates. As the peak seems to be strongly bound to the background and depends also on the strain amplitude (fig. 3), it cannot be interpreted by models of anelastic relaxation within the precipitates as it was the case in previous papers concerning anelastic effects after precipitation in $\mathrm{Al}-\mathrm{Mg}-\mathrm{Si}$ alloys [8,9]. It is more reasonable to interpret it as due to dislocation motion in a similar way as Pichler and co-authors [10-12] interpreted the peak, that they have observed in Al-Si alloys. These authors measured the damping spectra of single and polycrystalline of Al-Si alloys with incoherent Si particles and observed a relaxation peak around $450 \mathrm{~K}$. They proposed a model which explains the peak as due to the dragging of solute atoms by the dislocations, the activation energy being the core diffusion of the solute atoms. In the present case a similar interpretation can be proposed. The activation energy of $1.54 \mathrm{eV}$ (fig.4) is reasonable for the self diffusion energy or the diffusion energy of subsitutional atoms in aluminum.

Moreover, measurements performed as a function of the strain amplitude have shown a shift in the peak temperature when the applied stress is modified (fig. 5). From this shift it is possible to deduce the activation volume associated with the relaxation mechanism. A value of $70 b^{3}(b=$ Burgers vector) has been obtained, which seems reasonable for a dragging mechanism. Effectively, admitting that the yield stress of the alloy is about 200 $\mathrm{MPa}$, it is possible from the Orowan stress ( $\sigma_{0.2}=\mathrm{Gb} / 1$, where $\mathrm{G}$ is shear modulus) to deduce that the mean dislocation loop length, 1 , about $100 \mathrm{~b}$. Then the activation volume associated with the jump of the dislocation loop which drags one solute atom, would be $\sim 100$ $b^{3}$.

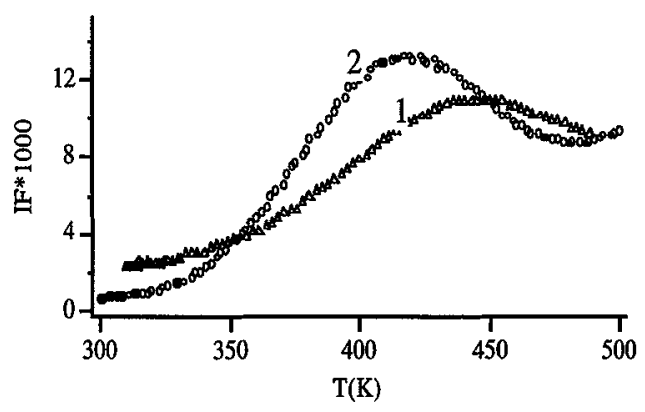

Figure 5: Effect of the strain amplitude on temperature position of the internal friction peak. Strain amplitudes are $2 \times 10^{-5}$ and $4 \times 10^{-4}$ for curves 1 and 2 respectively. Activation volume would be of $\sim 70 b^{3}$. 
The relaxation peak may then be due to the dragging at high temperature of the solute atoms by the dislocations. At $1 \mathrm{~Hz}$, the peak appears at $420 \mathrm{~K}$. At lower temperature, one observes a strong amplitude effect. It is then logical to interpret it by the breakaway of the dislocation [13,14] from these solute atoms which cannot follow the dislocation at a temperature lower than peak temperature. This breakaway phenomenon is activated at relatively high strain amplitude $\left(\sim 2 \times 10^{-3}\right)$ but leads to a high damping capacity $\left(\sim 10^{-2}\right)$.

Considering the results above mentioned, one remarks that this amplitude effect appears after precipitation, when the specimen has been aged in the temperature range of the lowest value of TEP. In this case, the solute concentration in the matrix which surrounds the precipitates would be minimum. The microstucture can be described as composed of semicoherent $\beta^{\prime}$ precipitates [15] which are susceptible to firmly pin the dislocation leading to a high value of the yield strength. As the solute concentration in the matrix is low, the dislocations loops are relatively free to vibrate between the precipitates. Though, if the matrix would be pure, the damping level would be very low. Effectively, as mentioned above, from the yield stress it is possible to derive the dislocation loop length, and taking into account a dislocation density of $10^{6} \mathrm{~cm}^{-2}$, it is easy to calculate the level of damping thanks to the string model $[13,14]$. One obtains a damping level of $1.5 \times 10^{-6}$, which is very low. This shows that another dissipation mechanism than the classical viscosity of pure aluminum has to be activated. Some soft pinning points must be on the dislocation loop allowing a breakaway dissipative mechanism. Increase of damping in AlMgSi alloy requires that dislocation loops, which are firmly pinned by the second phase precipitates, can interact with solute atoms in order to dissipate energy. The goal of the research is then to find the solute element and the correct concentration leading to a high damping capacity.

\section{CONCLUSIONS}

The mechanical loss spectrum of the aged AlMgSi alloys exhibits a damping peak around $420 \mathrm{~K}(\mathrm{f}=1 \mathrm{~Hz})$. This peak is interpreted by the dragging of solute atoms by the dislocations. In addition a strong dampingamplitude effect has been observed in a wide temperature range. For temperatures lower than the peak temperature, this can be attributed to the breakaway of the dislocations from solute atoms. This phenomenon leads to a high damping capacity in the high strain amplitude range $\left(>10^{-3}\right)$.

\section{Acknowledgments.}

This work has been supported by the Swiss Priority Program on Materials Research. Alusuisse Company is acknowledged for the specimen supply.

\section{References}

[1] Sugimoto K., Mem. Inst. Sci. Ind. Res., Osaka University 35 (1978) 31-44.

[2] De Batist R., J. Physique 44 (1983) C9:39-50.

[3] Ritchie I.G., Pan Z.L., Metall. Trans. 22A (1991) 607-616

[4] Schaller R., Van Humbeeck J., "High Damping Materials---HIDAMETS", Proc. International Summer School on Mechanical Spectroscopy, Chapt. 5.6, Cracow, 8-14 Sept. 1991 to be published.

[5] Zhang J.M., Perez R. J., Wong C. R., Lavernia E.J., Mater. Sci. \& Engin. R13 (1994) 325-390.

[6] Borrelly R., Mém. Sci. Revue Métall. 76 (1979) 37-49.

[7] Carreño-Morelli E., Ph.D. Thesis, National University of Córdoba, Argentina, 1994.

[8] Attardo M.J., Gallign J.M., Acta. Metall. 15 (1967) 393-395.

[9] Williams K.J., Acta Metall. 15 (1967) 393 395.

[10] Pichler A., Weller M., Artz E., Diehl J., Mater. Sci. Forum 119/121 (1993) 365-370.

[11] Pichler A., Weller M., Arzt E., Acta. Metall. 42 (1994) 3801-3809.

[12] Pichler A., Arzt E., Acta. Metall. 42 (1994) 3785-3800.

[13] Granato A., Lücke K., J. App. Phys. 27 (1956) 583-593.

[14] Granato A., Lücke K., J. App. Phys. 52 (1981) 7136-7142.

[15] Shchegoleva T.V., Phys. Met. \& Metallogr. 25 (1968) 56-64. 